\title{
LA HISTORIA \\ DEL PENSAMIENTO ECONOMICO \\ EN ESPAÑA *
}

JUAN HERNANDEZ ANDREU

Universidad Complutense de Madrid

El número 656 de la revista Información Comercial Española recoge un conjunto importante de estudios de Historia de las Doctrinas Económicas, cuyos autores tienen en común el hecho de pertenecer a lo que se viene denominando la «Escuela de Madrid» de Historia del pensamiento económico. Antes de reseñar, brevemente, los contenidos temáticos de los distintos artículos, haré algunas valoraciones sobre este grupo de estudiosos: vaya por delante que el espectro de investigadores que lo forman, o se relacionan con él, es más amplio que el aquí representado, lo cual es lógico, habida cuenta que se trata de una auténtica pléyade de analistas científicos que viene de tiempos atrás. Ya durante el curso 1968/1969, tuve oportunidad de seguir un curso de doctorado sobre «Economistas españoles del siglo xIX» a cargo del profesor don Pedro Schwartz, catedrático de la disciplina en la Universidad Complutense y uno de los académicos españoles de mayor prestigio en el ámbito de las universidades inglesas y norteamericanas; el profesor Schwartz es el impulsor del grupo, ya que en su seminario, desde entonces y hasta hoy en día, vienen forjándose la gran mayoría de las producciones científicas de estos estudiosos.

Los antecedentes de este quehacer universitario en la disciplina de Historia del Pensamiento Económico arrancan de profesores de la Facultad de Ciencias Económicas como Valentín Andrés Alvarez y, sobre todo, del doctor José Piera, quien, a su vez, promovió la idea de la presente publicación. Quiero destacar el alto nivel científico y el respeto al libre pensamiento que caracterizan al Seminario de Historia de las Doctrinas Económicas; los análisis y críticas, en el ámbito del mismo, son severos y los argumentos expuestos con rigor; las sesiones suelen ser interdisciplinares; y los principales instrumentos analíticos son los de la Teoría Económica, fundamentalmente, y los de la Historia Económica. Entre las Doctrinas Económicas, son objeto de especial atención las de los grandes autores clásicos y neoclásicos, sin desaten-

* Número monográfico de Intormación Comercial Española, 656, abril 1988, pp. 7-124. 
der ninguna de reconocimiento universal; las obras de los autores españoles se analizan, en su caso, por su específica contribución al pensamiento económico.

Consecuencia de regular debate científico son los estudios que se publican en el número de Información Comercial Española. Quiero advertir que por la obligada evaluación de carácter general que impone una publicación de múltiples contenidos como la presente, no entraré en ponderaciones y críticas pormenorizadas a cada artículo.

El profesor Victoriano Martín ofrece un fecundo análisis de los opúsculos de Juan Luis Vives, Del socorro a los pobres (1526), y de Domingo de Soto, Deliberación en la causa de los pobres (1545), que ante la concepción de progresismo, atribuida a Vives, y de conservadurismo, a Soto, fundamenta la existencia de una filosofía propia de un Estado intervencionista en el primero, frente a la defensa de un ideario liberal en el segundo.

El profesor Lucas Beltrán estudia el talante y la obra del llamado primer historiador general de España, que fue el padre Mariana, concluyendo, respecto al pensamiento económico que encierra el Tratado y discurso sobre la moneda del vellón (1605), que las concepciones del P. Mariana obedecen a un liberalismo incipiente, lo cual contradice las posiciones ideológicas de dicho autor en otras de sus publicaciones.

Doña Reyes Fernández Durán ofrece una documentada valoración biográfica de Gerónimo de Uztáriz (1670-1732); y el profesor Luis Perdices publica unos apuntes sobre la vida y escritos de Pablo de Olavide, con amplias y precisas referencias documentales, constiruyendo una gran aportación al conocimiento de las concepciones de este ilustrado.

El profesor Manuel Jesús González presenta un análisis de las posiciones de Campomanes y Jovellanos acerca de los condicionamientos que informan el marco institucional para el funcionamiento de un sistema de precios libres en la España del Antiguo Régimen; y señala que si bien ambos autores querían modernizar el país, no obstante, los argumentos de Jovellanos son más precisos que los de Campomanes a propósito de las limitaciones institucionales para la práctica de la economía de mercado.

El profesor Schwartz ofrece un valioso y extenso artículo sobre si el tipo de sociedad descrito por Jeremy Bentham, en el Código Constitucional, es auténticamente democrático o si, aunque de manera inadvertida, propone un despotismo democrático, la conclusión a la que llega es que se trata de lo segundo; dando un alcance actual a las reflexiones que se aducen; por otra parte, el estudio es también relevante por su precisa y amplia documentación.

El profesor Carlos Berzosa presenta un interesante análisis del circuito y la circulación del capital en la obra de Mar advierte la conexión mar- 
xiana de los procesos reales de producción con los de financiación y mercado; así como el alcance de estos mecanismos con el comportamiento y evolución del ciclo económico.

Es de previsible fecundidad el estudio del Dr. Fernando Méndez Ibisate sobre las teorías decimonónicas del dinero en el siglo $\mathrm{xx}$; las controversias doctrinales sobre la historia de las teorías monetarias reciben un tratamiento riguroso y bien expuesto.

El profesor Carlos Rodríguez Braun nos presenta un estudio ordenado sobre la biografía y la teoría de la Renta de Richard Jones, autor británico de la primera mitad del siglo pasado; asimismo estudia la armonía social y la influencia de Jones en Malthus, Mill, los neoclásicos, la escuela histórica $y$ el institucionalismo, y Marx.

Finalmente, don Manuel Santos Redondo aduce una síntesis de la teoría del empresario como factor de producción en el pensamiento económico de Frank H. Knight, en su Risk, Uncertainty and Profit (1965).

$\mathrm{Si}$ bien está distribuido en partes iguales el número de artículos referidos a autores españoles respecto a doctrinas de economistas extranjeros, los estudios de pensamiento económico del siglo xx se hallan en minoría en esta publicación. También son minoritarios los estudios sobre autores que se ocupan directamente del crecimiento económico a largo plazo, lo cual podría ser un infiel reflejo de la diversidad ideológica que efectivamente existe en el Seminario de Historia de las Doctrinas Económicas.

Los diversos artículos tienen un explícito apoyo bibliográfico; la edición está bien cuidada. La aportación científica de estas páginas ofrecidas por este grupo de estudiosos de la Historia del pensamiento económico es indiscutible. 